\title{
THE DIAGNOSIS OF PSORIATIC ARTHRITIS
}

\author{
P.S. HELLIWELL \\ Academic Unit of Musculoskeletal and Rehabilitation Medicine, University of Leeds, UK
}

\begin{abstract}
SUMMARY
For over 30 years investigators have used the simple but non-validated classification criteria suggested by Moll and Wright. Several authors have suggested modifications but most remain invalid or require HLA analysis. Now, a world wide initiative has developed new criteria (the CASPAR criteria) which include both clinical, laboratory and radiological features. These will require further study before they are fully adopted for future studies but their improved performance should result in less variation between study cohorts.
\end{abstract}

Key words: Psoriatic arthritis, classification criteria, diagnosis

\section{INTRODUCTION}

Most rheumatology clinicians would claim that they have little difficulty diagnosing psoriatic arthritis. However, this was not confirmed by a recent study performed in the Netherlands where rheumatologists often failed to examine for skin disease or neglected the significance of distal interphalangeal joint involvement (1).

In addition, a recent study from the UK found that 'experts' in this field may disagree about the diagnosis in 'grey' cases, cases where the characteristic clinical features are absent (2). A typical scenario is the example of seronegative symmetrical polyarthritis and psoriasis.

The mere presence of psoriasis is usually sufficient for a diagnosis of psoriatic arthritis to be made but, inevitably, there will be cases of true rheumatoid arthritis where co-incidental psoriasis occurs. Bedside diagnosis is, of course, a separate issue to classification and this article will focus on classification. Once classification criteria have been published clinicians frequently (mis) use them for clinic or bedside diagnosis but validated and agreed criteria should provide some uniformity for therapeutic trials and also a more homogenous group for laboratory studies.

Corresponding author:

Philip Helliwell

Academic Unit of Musculoskeletal

and Rehabilitation Medicine

University of Leeds,

36, Clarendon Road, Leeds LS2 9NZ

E-mail: p.helliwell@leeds.ac.uk

\section{HISTORICAL ASPECTS}

Up to 2006 virtually all published studies of psoriatic arthritis used the criteria suggested by Moll and Wright in their classic paper published in 1973 (3). The criteria are simple to use and specify three conditions: the presence of psoriasis, an inflammatory arthritis and a (usual) negative test for rheumatoid factor. Interestingly, people classified as psoriatic arthritis by subsequent authors appear to differ substantially from those included by Moll and Wright, particularly with reference to the number of involved joints - Moll and Wright found polyarthritis in $15 \%$ of cases whereas in later series $65 \%$ had polyarthritis (4-8). Further, later series included patients who were rheumatoid factor positive in up to $13 \%$ in some cases (4), and this raised the spectre of cases of seronegative (and in some cases seropositive) rheumatoid arthritis, with coincidental psoriasis, being classified as psoriatic arthritis. Moll and Wright, in their desire to keep the criteria simple and sensitive, may have omitted the other defining features of psoriatic arthritis, such as dactylitis and enthesitis, from their stated criteria yet while still using these in clinical practice.

In addition to the Moll and Wright criteria several other criteria sets have been proposed (4, 9-13). Until recently none of these were validated and none of these were founded on patient derived data. All were developed to add some specificity to the criteria, although at the cost of reduced sensitivity. Recently, these criteria sets have been compared, firstly in a retrospective cross-sectional study in two centres and secondly in a prospective 
Table I - The CASPAR criteria (15).

\begin{tabular}{|c|c|}
\hline \multicolumn{2}{|c|}{ Inflammatory articular disease (joint, spine, or entheseal) } \\
\hline $\begin{array}{l}\text { With } 3 \text { or more points from the following: } \\
\text { 1. Evidence of psoriasis (one of } \mathrm{a}, \mathrm{b}, \mathrm{c} \text { ) } \\
\text { (a) Current psoriasis* } \\
\text { (b) Personal history of psoriasis } \\
\text { (c) Family history of psoriasis }\end{array}$ & $\begin{array}{l}\text { Psoriatic skin or scalp disease present today as judged by a rheumatologist or dermatologist } \\
\text { A history of psoriasis that may be obtained from patient, family doctor, dermatologist, } \\
\text { rheumatologist or other qualified health-care provider } \\
\text { A history of psoriasis in a first or second degree relative according to patient report }\end{array}$ \\
\hline 2. Psoriatic nail dystrophy & $\begin{array}{l}\text { Typical psoriatic nail dystrophy including onycholysis, pitting and hyperkeratosis observed } \\
\text { on current physical examination }\end{array}$ \\
\hline 3. A negative test for rheumatoid factor & $\begin{array}{l}\text { By any method except latex but preferably by ELISA or nephelometry, according to the local } \\
\text { laboratory reference range }\end{array}$ \\
\hline $\begin{array}{l}\text { 4. Dactylitis (one of a, b) } \\
\text { (a) Current } \\
\text { (b) History }\end{array}$ & $\begin{array}{l}\text { Swelling of an entire digit } \\
\text { A history of dactylitis recorded by a rheumatologist }\end{array}$ \\
\hline $\begin{array}{l}\text { 5. Radiological evidence of juxta-articular } \\
\text { new bone formation }\end{array}$ & $\begin{array}{l}\text { Ill-defined ossification near joint margins (but excluding osteophyte formation) on plain xrays } \\
\text { of hand or foot }\end{array}$ \\
\hline $\begin{array}{l}\text { Specificity } 0.987 \text {, sensitivity } 0.914 \\
{ }^{*} \text { Current psoriasis scores } 2 \text { whereas all othe }\end{array}$ & \\
\hline
\end{tabular}

multi-centre design $(14,15)$. The specificity of all the criteria sets was found to be high but the sensitivity varied from 0.42 to 0.98 . Further, not all cases could be classified due to missing data - this was particularly true in the retrospective study where data was extracted from routine clinical case notes - and for the Fournié classification which included HLA status among its' criteria (13).

\section{NEW CRITERIA}

The CASPAR study group was established to derive new data driven classification criteria for psoriatic arthritis. Data were collected in 32 centres world wide by people with acknowledged expertise in this condition. On average each centre contributed 20 cases and 20 controls, the controls being cases of other inflammatory arthritis, with the additional stipulation that at least half of these should have rheumatoid arthritis. Data was collected to a standard format on consecutive clinic attendees with psoriatic arthritis (total included 588) and the next case of inflammatory arthritis (total 536). Altogether over 100 clinical, radiological and laboratory variables were collected. The new criteria were derived by logistic regression and CART analysis (as a cross check) and the performance of the new criteria compared to the other existing criteria. The new CASPAR criteria (Table I) gratifyingly have both characteristic dermatological, clinical and radiological features and have both high sensitivity and very high specificity (15). Perhaps the weakest aspect of the CASPAR criteria is the initial qualification criterion: inflammatory arthritis including spinal, peripheral and entheseal disease.

As cases were physician diagnosed and without other stipulation in the selection process it was impossible to be more precise with this description. In fact the majority cases had a peripheral arthritis pattern, although 72 had a combined axial/peripheral pattern, and 21 did not have any peripheral joint involvement at all. Of these 21, two had pure axial disease, 8 dactylitis only, 12 enthesitis only, and 10 inflammatory spinal symptoms (in combinations). A further concern is the applicability of the criteria to early disease, as the mean duration of disease of the cases was 12.5 years. However, early reports suggest that the criteria work equally well in early disease (Dafna Gladman, personal communication). It is of some additional concern that the criteria do not contain any of the spinal features, which most clinicians would use to distinguish psoriatic arthritis from rheumatoid arthritis. The reason for this resides in the composition of the controls for this study. About $70 \%$ of the controls had rheumatoid arthritis but $13 \%$ had ankylosing spondylitis so the statistical analyses were influ- 
enced against selecting spinal features as characteristic of psoriatic arthritis. Qualitative and quantitative differences in the spondylitis of psoriasis and classical ankylosing spondylitis remain unresolved.

\section{CONCLUSIONS}

For over 30 years investigators have used the simple but non-validated classification criteria suggested by Moll and Wright. Several authors have suggested modifications but most remain invalid or require HLA analysis. Now, a world wide initiative has developed new criteria which include both clinical, laboratory and radiological features. These will require further study before they are fully adopted for future studies but their improved performance should result in less variation between study cohorts.

\section{REFERENCES}

1. Gorter S, van der Heijde DMFM, vander Linden S, Houben H, Rethans J-J, Scerpbier AJJA et al. Psoriatic arthritis: performance of rheumatologists in daily practice. Ann Rheum Dis 2002; 61: 219-24.

2. Symmons DP, Lunt M, Watkins G, Helliwell PS, Jones SM, McHugh NJ et al. Developing classification criteria for peripheral joint psoriatic arthritis. Step I. Establishing whether the rheumatologists opinion on the diagnosis can be used as the "gold standard". Journal of Rheumatology 2006; 33: 552-7.

3. Moll JMH, Wright V. Psoriatic arthritis. Sem Arthr \& Rheum 1973; 3: 51-78.

4. Gladman DD, Shuckett R, Russell ML, Thorne JC, Schachter RK. Psoriatic arthritis (PSA) - an analysis of 220 patients. Quart J Med 1987; 238: 127-41.

5. Helliwell P, Marchesoni A, Peters M, Barker M, Wright $\mathrm{V}$. A re-evaluation of the osteoarticular manifestations of psoriasis [see comments]. British Journal of Rheumatology 1991; 30 (5): 339-45.

6. Biondi OC, Scarpa R, Pucino A, Oriente P. Psoriasis and psoriatic arthritis. Dermatological and rheumatological co-operative clinical report. Acta DermatoVenereologica 1989; Supplementum (146): 69-71.

7. Alonso JCT, Perez AR, Castrillo JMA, Garcia JB, Noriega JLR, Larrea CL. Psoriatic arthritis (PA): a clinical, immunological and radiological study of 180 patients. Brit J Rheum 1991; 30: 245-50.

8. Jones SM, Armas JB, Cohen MG, Lovell CR, Evison G, McHugh NJ. Psoriatic arthritis: outcome of disease subsets and relationship of joint disease to nail and skin disease. British Journal of Rheumatology 1994; 33 (9): 834-9.

9. Bennett RM. Psoriatic arthritis. In: McCarty DJ, editor. Arthritis and related conditions. Philadelphia: Lea and Febiger, 1979: 645.

10. Vasey FB, Espinoza LR. Psoriatic arthritis. In: Calin A, editor. Spondyloarthropathies. Orlando, Florida: Grune and Stratton, 1987: 151-85.

11. Dougados M, Van Der Linden S, Juhlin R, Huitfeldt B, Amor B, Calin A et al. The European Spondyloarthropathy Study Group preliminary criteria for the classification of spondyloarthropathy. Arthr Rheum 1991; 34: 1218-27.

12. McGonagle D, Conaghan P, Emery P. Psoriatic arthritis: a unified concept 20 years on. Arthritis and Rheumatism 1999; 42(6): 1080-6.

13. Fournie B, Crognier L, Arnaud C, Zabraniecki L, Lascaux-Lefebvre V, Marc V et al. Proposed classification criteria of psoriatic arthritis: a preliminary study in 260 patients. Revue du Rheumatisme (Engl Edn) 1999; 66 (10): 446-56.

14. Taylor WJ, Marchesoni A, Arreghini M, Sokoll K, Helliwell PS. A comparison of the performance characteristics of classification criteria for the diagnosis of psoriatic arthritis. Seminars in Arthritis and Rheumatism 2004; 34: 575-84.

15. Taylor WJ, Gladman DD, Helliwell PS, Marchesoni A, Mease P, Mielants $\mathrm{H}$ et al. Classification criteria for psoriatic arthritis: Development of new criteria from a large international study. Arthritis and Rheumatism 2006; 54 (8): 2665-73. 